\title{
Burkholderia thailandensis strain E555 is a surrogate for the investigation of Burkholderia pseudomallei replication and survival in macrophages
}

\author{
A. Kovacs-Simon ${ }^{1 *}$, C. M. Hemsley ${ }^{1}$, A. E. Scott ${ }^{2}$, J. L. Prior ${ }^{1,2}$ and R. W. Titball ${ }^{1}$
}

\begin{abstract}
Background: Burkholderia pseudomallei is a human pathogen causing severe infections in tropical and subtropical regions and is classified as a bio-threat agent. B. thailandensis strain E264 has been proposed as less pathogenic surrogate for understanding the interactions of B. pseudomallei with host cells.

Results: We show that, unlike B. thailandensis strain E264, the pattern of growth of B. thailandensis strain E555 in macrophages is similar to that of B. pseudomallei. We have genome sequenced B. thailandensis strain E555 and using the annotated sequence identified genes and proteins up-regulated during infection. Changes in gene expression identified more of the known B. pseudomallei virulence factors than changes in protein levels and used together we identified $16 \%$ of the currently known B. pseudomallei virulence factors. These findings demonstrate the utility of $B$. thailandensis strain E555 to study virulence of $B$. pseudomallei.

Conclusions: A weakness of studies using B. thailandensis as a surrogate for B. pseudomallei is that the strains used replicate at a slower rate in infected cells. We show that the pattern of growth of $B$. thailandensis strain E555 in macrophages closely mirrors that of $B$. pseudomallei. Using this infection model we have shown that virulence factors of $B$. pseudomallei can be identified as genes or proteins whose expression is elevated on the infection of macrophages. This finding confirms the utility of B. thailandensis strain E555 as a surrogate for B. pseudomallei and this strain should be used for future studies on virulence mechanisms.
\end{abstract}

Keywords: Burkholderia pseudomallei, Burkholderia thailandensis strain E555, Transcriptome, Proteome, Virulence

\section{Background}

The bacterial pathogen Burkholderia pseudomallei causes meliodosis, a severe disease of humans in tropical and subtropical regions [1-3]. The clinical manifestations of melioidosis range from an acute sepsis to chronic localised disease to latent infection, which can reactivate decades later from an as yet unknown tissue reservoir $[4,5]$. Community-acquired disease is most likely a consequence of the bacterium in soil or water entering through cuts or skin abrasions. In small animal models of disease, the bacterium is much more infective

\footnotetext{
* Correspondence: Andrea.Kovacs-Simon@exeter.ac.uk

${ }^{1}$ College of Life and Environmental Sciences, University of Exeter, Geoffrey

Pope Building, Stocker Road, Exeter EX4 4QD, UK

Full list of author information is available at the end of the article
}

by the airborne or intranasal routes [6,7]. This might be consistent with the reported cases of disease in apparently healthy US helicopter crew during the Vietnam War, as a consequence of the inhalation of soil-derived dusts containing bacteria [8]. The bacterium is considered a bio-threat agent because of the high infectivity by the airborne route $[2,9]$. A recent study has estimated that worldwide there are 165,000 human melioidosis cases and 89,000 deaths per year [1]. There is no licensed vaccine for the prevention of disease [10], and the bacterium is inherently resistant to many antibiotics $[2,11]$. Against this background, there is an urgent need for medical countermeasures to the disease, and the development of new approaches to disease control will be dependent on an understanding of the mechanisms

(c) The Author(s). 2019 Open Access This article is distributed under the terms of the Creative Commons Attribution 4.0 International License (http://creativecommons.org/licenses/by/4.0/), which permits unrestricted use, distribution, and reproduction in any medium, provided you give appropriate credit to the original author(s) and the source, provide a link to the Creative Commons license, and indicate if changes were made. The Creative Commons Public Domain Dedication waiver (http://creativecommons.org/publicdomain/zero/1.0/) applies to the data made available in this article, unless otherwise stated. 
by which $B$. pseudomallei establishes infection. Whilst a range of studies have characterized some of the virulence factors of $B$. pseudomallei [2, 12-14], it is also clear that a much broader range of genes and proteins are implicated in playing a role in disease $[13,15,16]$. However, studies on virulence of the bacterium are necessarily constrained by the requirement to handle the bacterium under containment level 3 conditions.

Burkholderia thailandensis is a close relative of $B$. pseudomallei and is also found in the soil in tropical regions of the world [17]. The genomes of B. pseudomallei and B. thailandensis are very similar with two highly syntenic chromosomes, which have similar numbers of coding regions, similar assignments of encoded proteins to families and similar numbers of horizontally acquired genomic islands [18]. However, infections of humans with $B$. thailandensis are rare and the bacterium can be handled outside of a high containment laboratory. Several previous studies have used $B$. thailandensis as a surrogate for $B$. pseudomallei, to study virulence mechanisms [19-37]. These studies have used B. thailandensis isolates, such as strain E264, that replicate more slowly than B. pseudomallei in cell cultures [38, 39]. These strains lack the capsular polysaccharide of B. pseudomal$l e i$, which is a key virulence determinant [14, 40]. However, a minority of $B$. thailandensis strains possess a $B$. pseudomallei-like capsule $[21,40]$, though they are not virulent in murine models of disease [40]. In this study we set out to assess one of these strains as a surrogate for B. pseudomallei, in the hope that this would more faithfully mimic the behavior of $B$. pseudomallei in cell culture, and could be used to study virulence.

\section{Results}

\section{Genome sequencing}

We selected B. thailandensis strain E555 (a natural isolate previously described by Sim et al. [40]) for our study because, unlike most $B$. thailandensis strains, it possesses a capsular polysaccharide which is similar to $B$. pseudomallei [40, 41]. We sequenced the B. thailandensis strain E555 available in our laboratory. Sequence data are available at DDBJ/ENA/GenBank under the accession SJET00000000. In B. pseudomallei, the wcb operon, which includes capsular polysaccharide genes, consists of 20 genes (wcbA-T [42, 43]) of which 19 are also encoded in the $B$. thailandensis strain E555 genome ( $w c b N$ is not present) (Additional file 3: Table S1 C). In addition to the capsule, $B$. thailandensis strain E555 has been shown to exhibit several $B$. pseudomallei-like phenotypes such as colony wrinkling, resistance to human complement binding, and survival in macrophages [40]. However, despite these similarities, $B$. thailandensis strain E555 shows the same level of virulence in mice as other B. thailandensis strains [40]. Using RAST [44] we predicted 6508 open reading frames in our B. thailandensis strain E555 genome sequence data (ORFs; Additional file 3: Table S1 A and B). We compared the amino acid sequences of $B$. pseudomallei strain K96243 proteins to $B$. thailandensis strain E555 and B. thailandensis strain E264 and found 4535 proteins in both $B$. thailandensis strain E555 and strain E264, 94 only in $B$. thailandensis strain E555 and 380 only in B. thailandensis strain E264. The remaining 914 proteins were not found in either B. thailandensis strain and of these 233 were encoded by genes located in the genome islands in B. pseudomallei.

\section{Infection model}

We first infected J774A.1 mouse macrophage cells with B. thailandensis strain E555 and the number of intracellular bacteria was measured at intervals. We compared this data with data previously obtained in our laboratory using an identical method with $B$. pseudomallei strain K96243 or B. thailandensis strain E264 which is commonly used as a surrogate for B. pseudomallei [39]. B. thailandensis strain E555 and B. pseudomallei strain K96243 had similar growth rates in macrophages (doubling times are $2.02 \mathrm{~h}$ for B. pseudomallei strain K96243 and $2.06 \mathrm{~h}$ for B. thailandensis strain E555 over the $4 \mathrm{~h}$ period between $4 \mathrm{~h}$ and $8 \mathrm{~h}$ post-infection), while the growth of $B$. thailandensis strain E264 was slower and showed a different growth pattern ( $p$ values between B. pseudomallei strain $\mathrm{K} 96243$ and B. thailandensis strain E264 were $p<0.001$ at $4 \mathrm{~h}, 6 \mathrm{~h}$ and $8 \mathrm{~h}$ post-infection, see Fig. 1).

\section{Analysis of the global bacterial transcriptome}

To investigate how B. thailandensis strain E555 adapts to the intracellular environment in J774A.1 mouse macrophage cells, the transcriptional and translational landscapes of the bacteria were profiled, using RNA-seq or mass spectrometry, after overnight growth in broth culture and during macrophage infection. Nine genes (Additional file 4: Table S2) were selected to validate the data generated from the RNA-seq study using RT-qPCR (the 23S rRNA was used as an internal control) $[45,46]$ (Fig. 2).

We identified broadly similar numbers of genes expressed in broth-cultured bacteria $(n=5071)$ or in bacteria from macrophages $(n=4378$ and $n=5112$ at 5 and $6 \mathrm{~h}$ post-infection) and most $(n=3893)$ were expressed in all 3 samples (Fig. 3 a and Additional file 5: Table S3). The abundance of transcripts at $5 \mathrm{~h}$ or $6 \mathrm{~h}$ post-infection (Fig. 3 a) showed a high correlation $(\mathrm{R}=$ 0.904; Additional file 1: Figure S1). Unique transcripts were more abundant at $6 \mathrm{~h}(n=329)$ than at $5 \mathrm{~h}(n=91)$ post-infection indicating that the adaptation of the bacteria to the intracellular environment was still in 


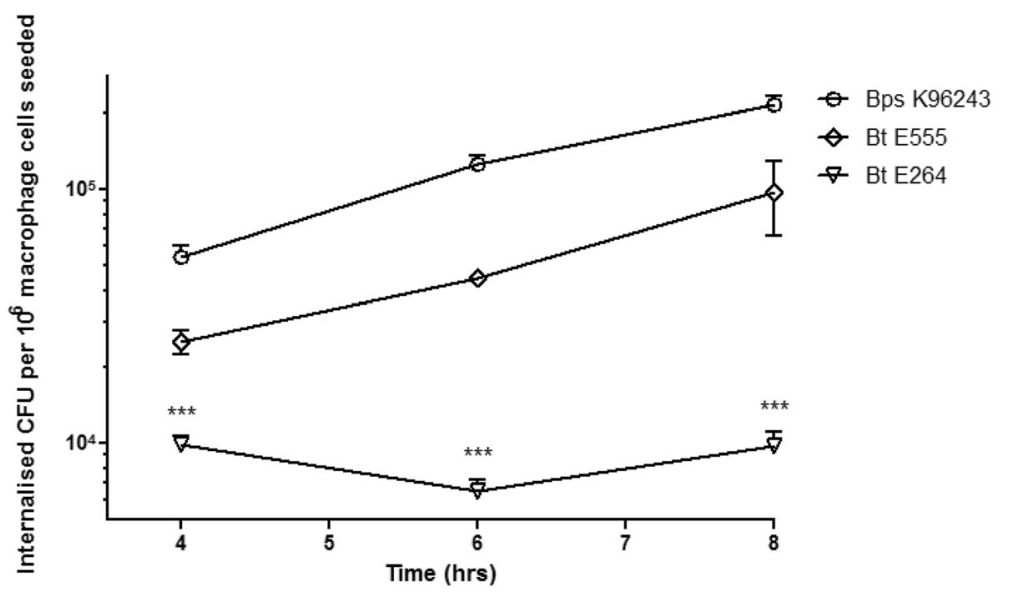

Fig. 1 Intracellular survival of Burkholderia strains in mouse macrophages. J774A.1 mouse macrophages were exposed to B. thailandensis strain E555 at an $\mathrm{MOl}$ of 10 for $2 \mathrm{~h}$. Following removal of the extracellular bacteria, infected macrophage cells were incubated with kanamycin ( $1 \mathrm{mg} / \mathrm{ml}$ in the first $2 \mathrm{~h}$ and $0.25 \mathrm{mg} / \mathrm{ml}$ afterwards) for 1, 2, 4 and $6 \mathrm{~h}$ and the mean numbers (with standard errors of the mean) of intracellular bacteria were determined. B. thailandensis strain E264 and B. pseudomallei strain K96243 values were adapted from Wand et al. [39]. There was no statistically significant difference between the growth rate of B. thailandensis strain E555 and B. thailandensis strain E264, or between the growth rate of $B$. thailandensis strain E555 and B. pseudomallei strain K96243 at any time point $(p>0.05)$. In contrast, the difference between the growth rate of B. pseudomallei strain $\mathrm{K} 96243$ and B. thailandensis strain E264 was significant: $p<0.001$ at $4 \mathrm{~h}, 6 \mathrm{~h}$ and $8 \mathrm{~h}$ post-infection, (indicated by ***)

progress between $5 \mathrm{~h}$ and $6 \mathrm{~h}$ post-infection. Expression of all of the $w c b$ genes $(n=19)$ encoded in the B. thailandensis strain E555 genome was detected in the transcriptomes of bacteria grown in broth and bacteria grown in macrophages (at $5 \mathrm{~h}$ and $6 \mathrm{~h}$ post-infection) (Additional file 7: Table S5.F). Overall, we concluded that the RNA-seq analysis provided a robust picture of the $B$. thailandensis transcriptome.

\section{Analysis of the global bacterial proteome}

For proteomics, we used an immunomagnetic method to first purify bacterial cells from infected macrophages. The protocol was assessed by visualising the protein extracts separated by SDS-PAGE. We tested three different antibodies against lipopolysaccharide, capsular polysaccharide or against $B$. pseudomallei cells, each conjugated separately onto magnetic beads. Using

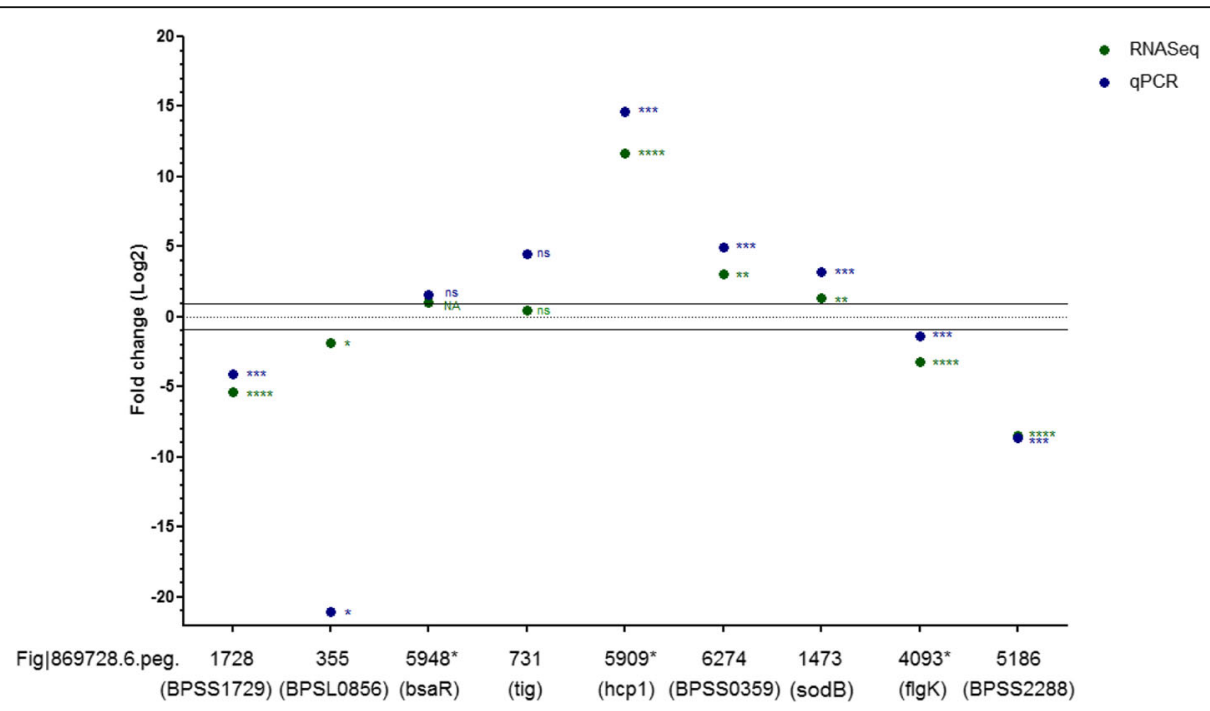

Fig. 2 Validation of RNASeq data by RT-qPCR. RNASeq (green) and RT-qPCR (blue) data at $6 \mathrm{~h}$ post-infection in macrophages. Tested genes: [i] 3 genes (Fig|869,728.6.peg.5909*, 6274, 1473) with significantly increased, [ii] 4 genes (Fig|869,728.6.peg.4093*, 5186, 1728, 355) with significantly decreased and [iii] 2 genes (Fig|869,728.6.peg.5948*, 731) without significantly increased level of expression during macrophage infection (a known virulence factor* was included in each group). B. pseudomallei homologs of these genes are shown in brackets. Internal control: 235 rRNA. Expression data is detailed in Additional file 4: Table S2. Horizontal lines show 2-fold change in expression cut-off. Asterisks on the graph indicate statistical significance 


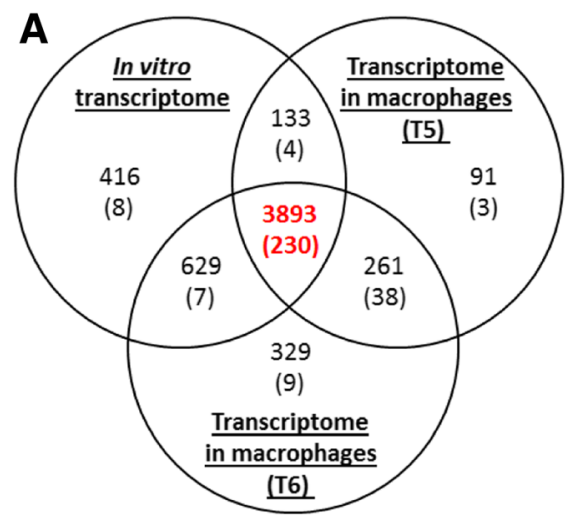

B

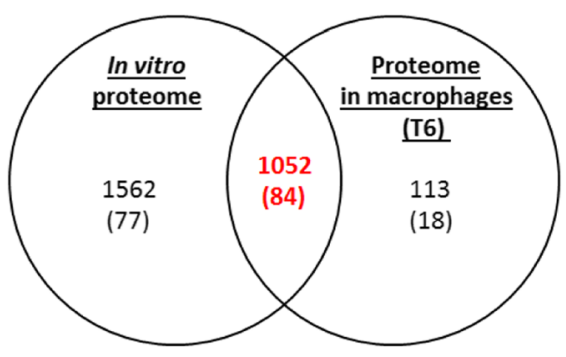

Fig. 3 Venn diagram of the transcriptional and translational landscapes of B. thailandensis strain E555 grown in vitro in LB broth and in macrophages. a Transcriptome. $\mathbf{b}$ Proteome. Figures in brackets indicate numbers of known virulence factors

antibodies against capsular polysaccharide, with an incubation time of $25 \mathrm{~min}$ at $4^{\circ} \mathrm{C}$, was the most efficient way of recovering bacteria from macrophage lysates (data not shown). Bacterial proteins were then identified by mass spectrometry (Additional file 6: Table S4). We detected lower numbers of proteins than corresponding gene transcripts. For over $90 \%$ of the proteins we identified the corresponding mRNA transcripts but conversely we could not detect the proteins corresponding to the majority of the transcripts (Fig. 4). These transcripts were not close to the limits of detection, suggesting that the inability to detect the corresponding protein was not linked to low levels of gene expression (Additional file 1: Figures S2 and S3). In contrast to the transcriptome data, not all of the proteins encoded by the $w c b$ operon were found in the proteome; we detected 12 in broth grown bacteria and 7 in bacteria isolated from macrophages (Additional file 7: Table S5.F).

Compared with transcriptome mapping, our proteomic analysis revealed the over-representation of cytoplasmic proteins. In contrast, proteins of unknown location were under-represented compared with transcriptome data sets (Fig. 5), possibly reflecting the limitations of pSORTb in predicting exported proteins [47], which would be difficult to detect in our proteome samples.

\section{Intracellular metabolism}

We investigated which cellular processes are required and which are dispensable in bacteria during infection of macrophages. We found up-regulation, of several fatty acid biosynthetic enzymes both in the $6 \mathrm{~h}$ transcriptome and in the $6 \mathrm{~h}$ proteome. Genes encoding proteins with roles in the valine, leucine and isoleucine biosynthetic and degradation pathways were also up-regulated at $6 \mathrm{~h}$ post-infection. In addition, four $(\arg T$, hisM, hisQ, hisP) out of five components of a lysine, arginine, ornithine and histidine $\mathrm{ABC}$-type transporter and a branched chain amino acid transporter (livK, livH, livM, livG, livF) were up-regulated $6 \mathrm{~h}$ after infection. We found down-regulation of a number of genes involved in nitrogen metabolism (metabolic enzymes and two-component systems). Linked to this pathway, glutamate metabolism was down-regulated. Finally our findings that cysteine and methionine metabolism were downregulated in bacteria isolated from macrophages suggests that these pathways are dispensable during infection.
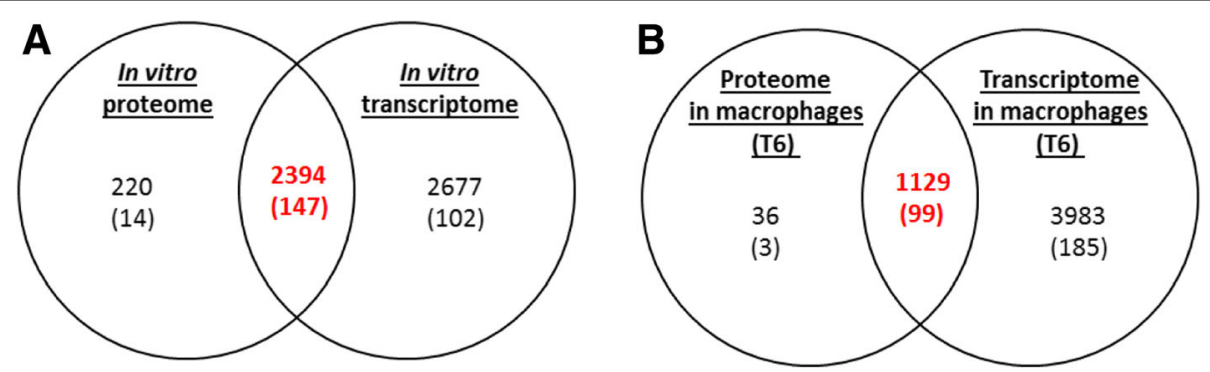

Fig. 4 Correlation between the transcriptional and translational landscapes of B. thailandensis strain E555 grown in vitro in LB broth or in macrophages. Venn diagram of the transcriptome and the proteome of B. thailandensis strain E555 (a) during in vitro (broth) growth or (b) during in vivo (macrophage) growth. Figures in brackets indicate the numbers of known virulence factors 


\section{A Genes expressed in vitro}

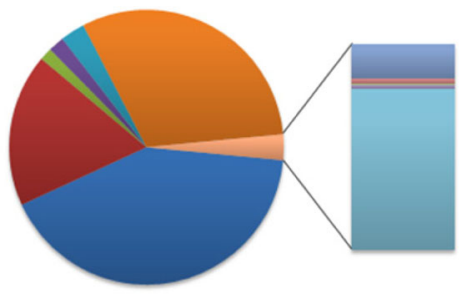

B Genes expressed $6 \mathrm{~h}$ post-infection

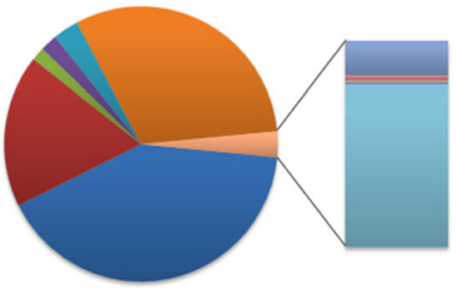

- Cytoplasmic
- Cytoplasm icMembrane

axtracellular

- OuterMembrane

a Periplasm ic

anknown

\section{Proteins expressed in vitro}

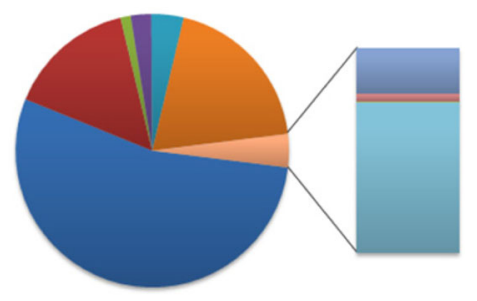

D Proteins expressed $6 \mathrm{~h}$ post-infection

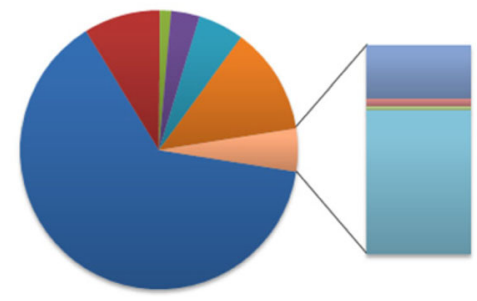

- Multiple location, predominantly

= Cytoplasmic*

a CytoplasmicMembrane*

Extrace llular*

= OuterMembrane*

= Unknown*

Fig. 5 Distribution of the cellular localisation of B. thailandensis strain E555 transcripts and proteins detected in culture and in infected macrophages. a Bacterial transcripts detected during in vitro growth in culture. $\mathbf{b}$ Bacterial transcripts detected $6 \mathrm{~h}$ after infection of macrophages. c Bacterial proteins detected during in vitro growth in culture. $\mathbf{d}$ Bacterial proteins detected $6 \mathrm{~h}$ after infection of macrophages

\section{Comparison of the significantly regulated transcriptome and proteome}

We next identified genes and proteins that were significantly $(p<0.05)$ up- or down-regulated at least two-fold in bacteria isolated from macrophages, compared with broth-cultured bacteria. We found that $11 \%$ of genes (265 up-regulated and 438 down-regulated) were differentially regulated at $5 \mathrm{~h}$ post-infection (Additional file 7: Table S5), and 15\% of genes (396 up-regulated and 583 down-regulated) were differentially regulated at $6 \mathrm{~h}$ post-infection (Additional file 7: Table S5 and Additional file 1: Figure S4.A). A total of 242 genes were up-regulated at both $5 \mathrm{~h}$ and $6 \mathrm{~h}$ post-infection. 23 genes were up-regulated only at $5 \mathrm{~h}$ post-infection and 154 genes were up-regulated only at $6 \mathrm{~h}$ post-infection. Among the 23 genes, 6 were known virulence factors of which 5 are components of the T3SS-3. Despite the larger number of up-regulated genes, only an additional 10 genes are known virulence factors of the 154 genes specific for $6 \mathrm{~h}$ post-infection (Additional file 7: Table S5.D). For our subsequent studies we used transcript data at $6 \mathrm{~h}$ post-infection.
In parallel, the proteomic landscape was investigated. We applied the same statistical criteria as with the transcriptomic data and identified 109 up-regulated and 364 down-regulated proteins $6 \mathrm{~h}$ post-infection (Additional file 7: Table S5 and Additional file 1: Figure S4.B). The number of up- or down-regulated proteins was smaller than the number of up- or down-regulated genes (Fig. 6). At $6 \mathrm{~h}$ post-infection we found $45 \%$ overlap between significantly up-regulated proteins and genes and $34 \%$ overlap between significantly down-regulated proteins and genes (Fig. 6). We found one up-regulated protein but with decreased corresponding mRNA, and 16 genes with decreased protein levels but with increased corresponding mRNA levels (Additional file 7: Table S5).

The groups which showed the greatest degree of enrichment in bacteria isolated from macrophages were genes encoding proteins involved in translation, and proteins involved in post-translational modification functions (Fig. 6 a). Proteins associated with amino acid transport and metabolism, and energy production were over-represented in the significantly down-regulated proteome but not in the significantly down-regulated transcriptome (Fig. 7 b). 

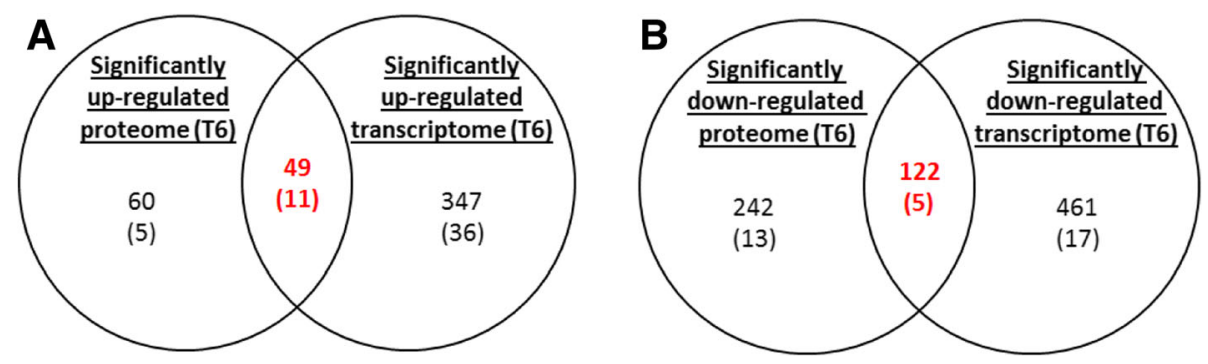

Fig. 6 Comparison of the significantly regulated genes and proteins during macrophage infection. a Over-expressed genes and proteins. b Repressed genes and proteins. Figures in brackets indicate the numbers of known virulence factors

\section{Virulence factors}

We compiled a list of 326 genes encoding virulence factors of B. pseudomallei which had been identified from previous experimental studies (Additional file 2: Supplementary References, Additional file 8: Table S6.A). Of these we found 267 in both $B$. thailandensis strain E555 and strain E264, 17 only in B. thailandensis strain E555 and 19 only in B. thailandensis strain E264. The remaining 23 virulence-associated factors were not found in either B. thailandensis strain (Additional file 8:

\section{A Significantly up-regulated genes and proteins}

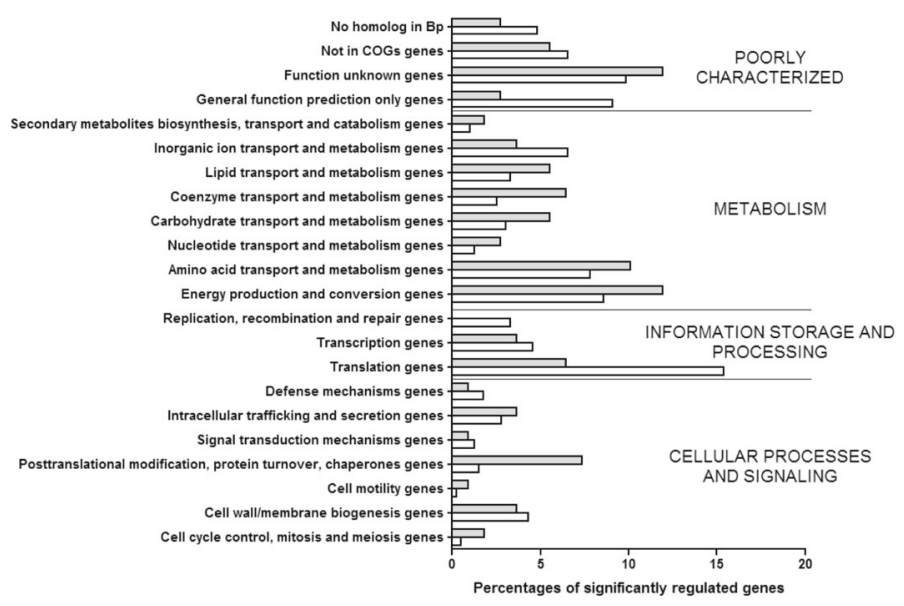

B Significantly down-regulated genes and proteins

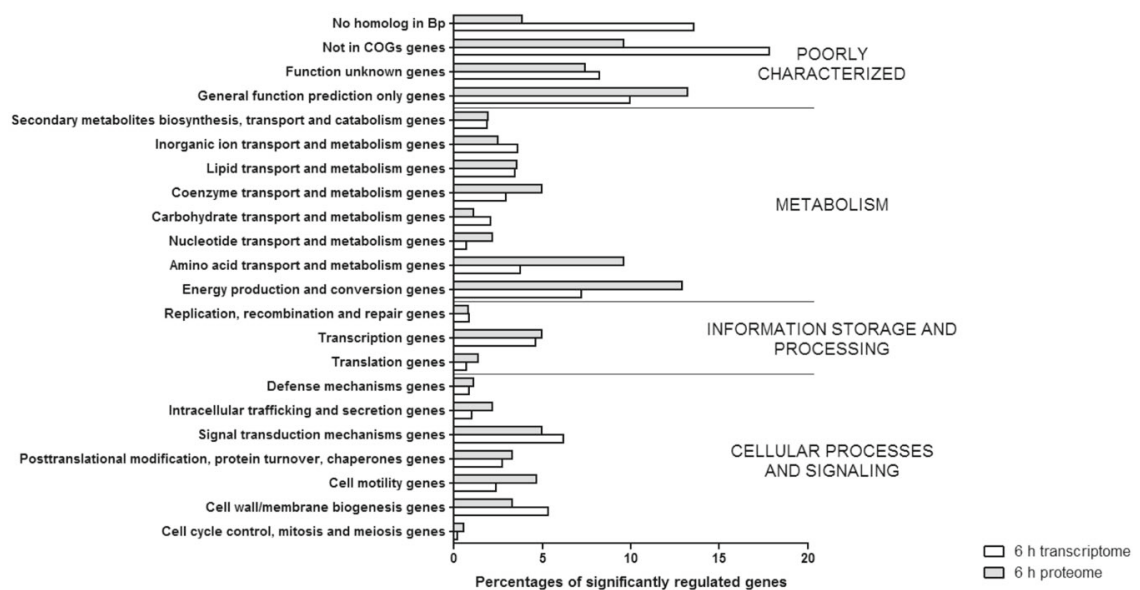

Fig. 7 Functional classification by COG designation of B. thailandensis genes and proteins significantly regulated during macrophage infection. Bars indicate percentages of genes or proteins relative to the total number genes and proteins significantly up-regulated (a) or down-regulated (b) 
Table S6). Of the 17 candidate virulence-associated factors found in both B. thailandensis strain E555 and B. pseudomallei but not in B. thailandensis strain E264, 9 are implicated in capsule biosynthesis, 6 genes encoded hypothetical proteins, 1 encoded a cell surface protein and 1 a non-ribosomal peptide synthetase. Of the 23 virulence-associated factors found only in B. pseudomallei strain K96243, 16 are hypothetical proteins or have either unknown or predicted function, 6 are predicted to be involved in transport, metabolism or catabolism of amino acids, lipids or secondary metabolites, and 1 is predicted to have a role in intracellular trafficking and secretion. These proteins might merit further attention as potential virulence determinants of $B$. pseudomallei. All or most of the genes in T6SS-1, T6SS-2, T6SS-3, T6SS-5 and T6SS- 6 are present in the genome of the $B$. thailandensis strain E555 but the T6SS-4 locus is missing (only two genes, the homologs of BPSS0166 and BPSS0185, are present).

In bacteria isolated from macrophages at $6 \mathrm{~h}$ post-infection expression of 284 of the virulence associated genes and 102 of the virulence associated proteins were detected (Fig. 4 b). Most (97\%) of the virulence-associated factors detected in the proteome were also detected in the transcriptome (Fig. 4 b). Of these, 47 genes and 16 proteins were up-regulated compared to broth grown bacteria (Fig. 6 a) and some virulence-associated factors were down-regulated (Fig. 6 b).

We found that 14 (56\%) of the 25 most highly up-regulated genes in $B$. thailandensis isolated from macrophages are known virulence factors of B. pseudomallei (Table 1). 11 of these genes encode components of the type VI secretion system-1 (T6SS-1) (Fig. 8 b) and the remaining genes encode $\mathrm{BsaN}, \mathrm{BimA}$ and $\mathrm{BprB}$ which are associated with virulence $[13,48-50]$. We also found that 10 of the 30 type III secretion system-3 (T3SS-3) genes were upregulated at $6 \mathrm{~h}$ post-infection (Fig. 8 a, Additional file 5: Table S3.D and Additional file 7: Table S5). One of the T3SS-3 genes (bsaN) was in the 25 most up-regulated genes (Table 1). RT-PCR data validated the up-regulation of $b s a R$, a component of the T3SS-3, and tssD-5 (hcp1), a component of the T6SS-1 (Fig. 2).

Four genes involved in iron acquisition were up-regulated in B. thailandensis strain E555 isolated from macrophages (Table 1; Bt E555 fig|869,728.6.peg.2756, 3100, 6277 and 3095; in B. pseudomallei BPSS0244, BPSL1779, BPSS0362 and BPSL1783, respectively) highlighting the importance of iron acquisition during infection.

The known importance of lipopolysaccharide [51] during infection by $B$. pseudomallei was mirrored by our finding of increased expression of the $r f b A-r f b B$ lipopolysaccharide $A B C$-transporter genes and increased expression of lipopolysaccharide biosynthetic genes and proteins in B. thailandensis strain E555 within macrophages. We also found up-regulation of $B$. thailandensis strain E555 fig|869,728.6.peg.5896 (BPSS1490 in B. pseudomallei) which encodes a peptidoglycan biosynthetic enzyme (Table 1 ). Of the capsule genes only $w c b A$ and $w c b K$ were significantly up-regulated (in the $6 \mathrm{~h}$ transcriptome and in the $6 \mathrm{~h}$ proteome, respectively).

The role of the SyrP-like protein Bt E555 fig|869,728.6.peg.3093 (BPSL1785 in B. pseudomallei) in virulence has not been tested experimentally in $B$. pseudomallei but there is evidence that it plays a role in the virulence of Pseudomonas syringae through the control of syringomycin production [52] and this gene was highly up-regulated in B. thailandensis strain E555 isolated from macrophages (Table 1).

Using our data we investigated whether up-regulated genes or up-regulated proteins were more likely to be virulence-associated factors. Significantly up-regulated genes identified $16 \%$ of the known virulence-associated factors, whilst significantly up-regulated proteins revealed only 5\% (Table 2 and Additional file 9: Table S7). However, the proteome analysis identified virulence factors with higher degree of confidence than the transcriptome analysis (14.7\% versus $11.9 \%)$. Combining the significantly up-regulated gene and protein datasets did not significantly improve the predictive power. But looking at the genes common in both the significantly up-regulated transcriptome and the significantly up-regulated proteome increased the likelihood of detection of virulence factors (22\%; Table 2). In comparison, the likelihood of randomly identifying a virulence-associated factor from the genome is approximately $5 \%$.

Some proteins, such as those which are membrane located or secreted, are difficult to recover while the corresponding transcripts are not subject to these constraints. Since the most likely cellular locations of virulence factors are at the cell surface and in the extracellular milieu, this might limit the utility of proteomics for the identification of virulence factors. However, extracellular, outer membrane and periplasmic proteins were found in similar proportions in the proteomes and in the corresponding transcriptomes. Nevertheless, all proteins are initially translated in the cytoplasm allowing their detection in this cellular compartment. Therefore, proteome analysis might also provide confident data for identification of classic virulence candidates, especially because the majority of cellular processes occur at protein level and not at transcript level.

\section{Discussion}

Central to this study is the proposition that B. thailandensis is a surrogate for understanding the interactions of $B$. pseudomallei with host cells. Most previous studies have used B. thailandensis strain E264 for these studies, 


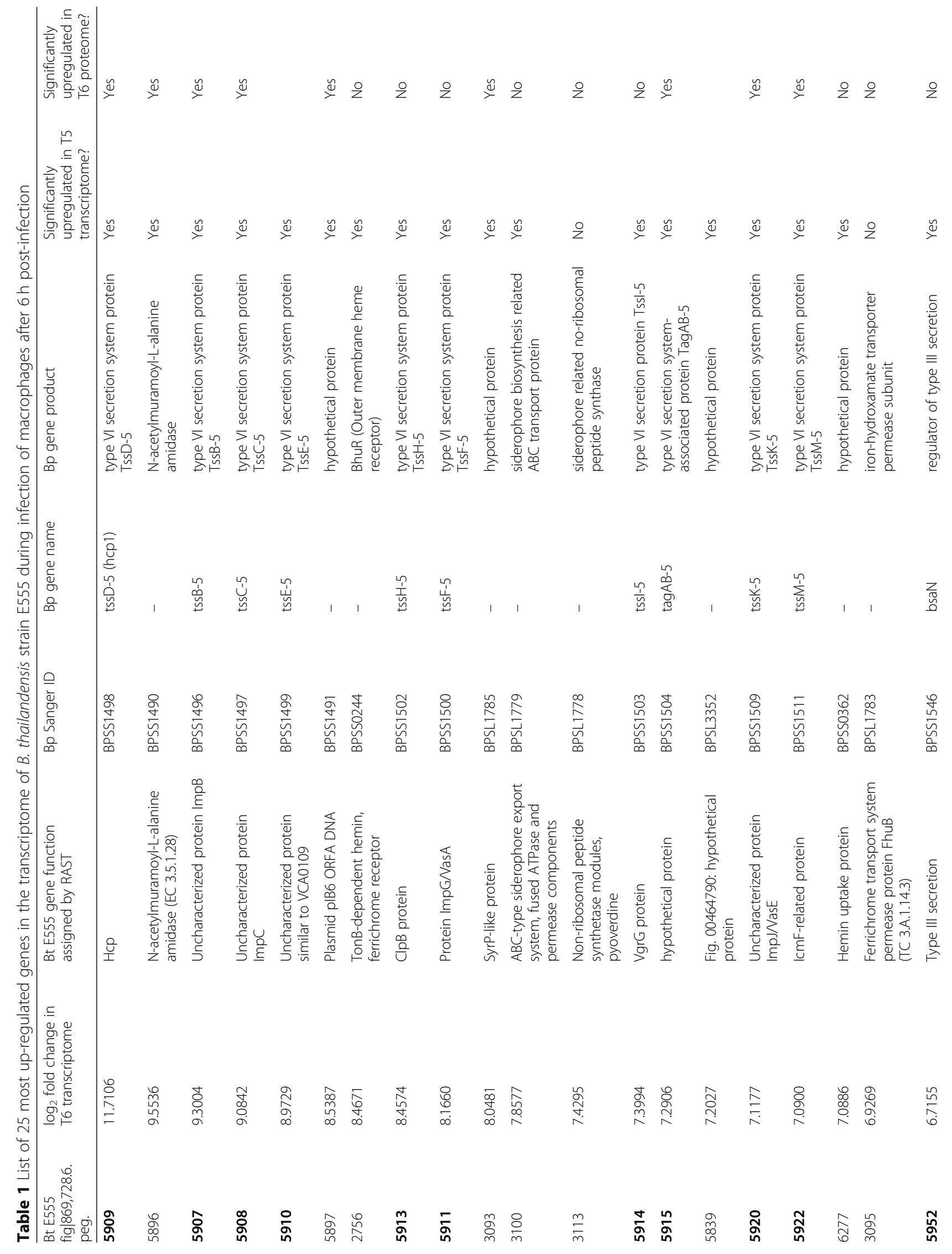




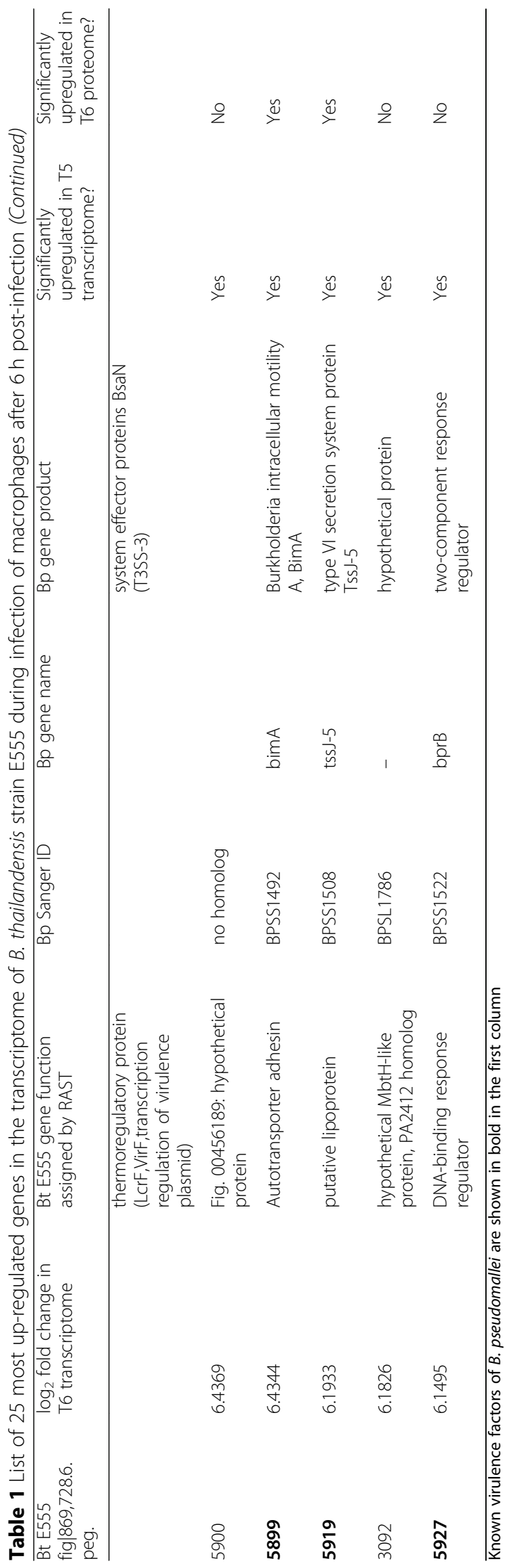



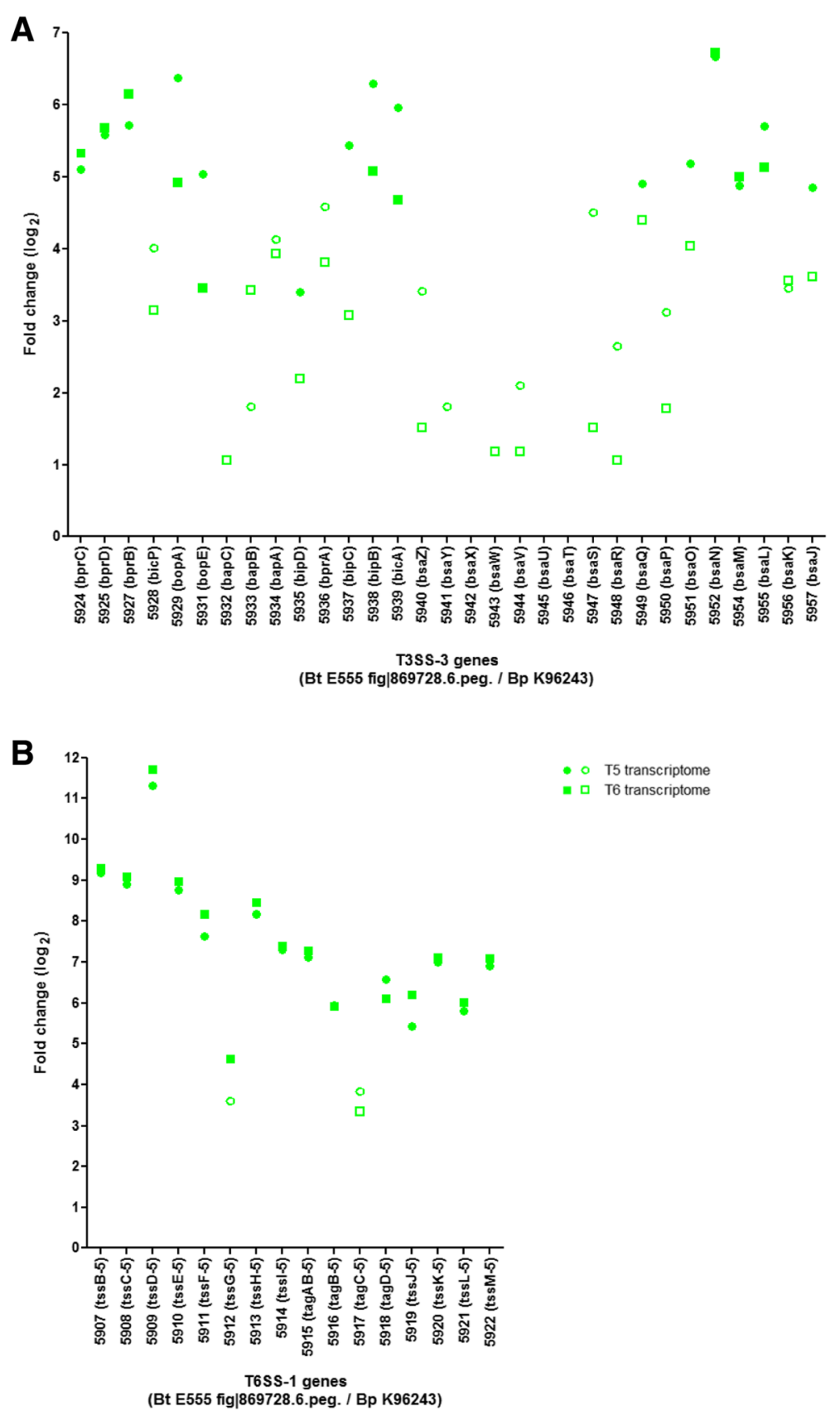

Fig. 8 Expression of the T3SS and T6SS-1 genes in the bacterial transcriptome during infection of macrophages. Up-regulation of the (a) T3SS and the (b) T6SS-1 genes. Homologs of the T3SS and T6SS-1 genes in B. pseudomallei are shown in brackets. Green circles: data for $5 \mathrm{~h}$ post-infection, green rectangles: data for $6 \mathrm{~h}$ post-infection, filled shapes represent significant up-regulation. Data was taken from Additional file 7: Table S5

but our work reveals that unlike $B$. thailandensis strain E264, B. thailandensis strain E555 grows at similar rate to $B$. pseudomallei in macrophages. A previous report showed that a B. pseudomallei mutant lacking capsular polysaccharide showed no difference in intracellular growth rate compared to the wild type [53]. Therefore the similar behaviour of $B$. thailandensis strain E555 to B. pseudomallei in host cells is unlikely to be due simply to the presence of the similar capsule in these different bacteria. Consistent with this we find that the overall genetic makeup of B. thailandensis strain E555 is more similar to that of B. pseudomallei strain K96243 than to the overall genetic makeup of $B$. thailandensis strain E264.

In this study we also compared the relative utilities of transcriptomic or proteomic approaches to identify 
Table 2 Summary of bacterial virulence factors detected in the transcriptome and in the proteome during infection of macrophages

\begin{tabular}{|c|c|c|c|c|c|}
\hline \multirow[t]{2}{*}{ Groups } & \multirow[t]{2}{*}{ Description } & \multirow{2}{*}{$\begin{array}{l}\text { Total number } \\
\text { of genes }\end{array}$} & \multirow{2}{*}{$\begin{array}{l}\text { Number of } \\
\text { virulence factors }\end{array}$} & \multicolumn{2}{|l|}{ Virulence factors in } \\
\hline & & & & $\begin{array}{l}\text { proportion of the total known } \\
\text { virulence factors in } \\
\text { B. thailandensis E555 (302) }\end{array}$ & $\begin{array}{l}\text { proportion of the genes } \\
\text { detected in the group } \\
\text { (column 3) }\end{array}$ \\
\hline A & Significantly up-regulated in the transcriptome & 396 & 47 & $15.6 \%$ & $11.9 \%$ \\
\hline B & Significantly up-regulated in the proteome & 109 & 16 & $5.3 \%$ & $14.7 \%$ \\
\hline$A+B$ & All genes in Groups A and B & 456 & 52 & $17.2 \%$ & $11.4 \%$ \\
\hline$A=B$ & Common genes in Groups A and B & 49 & 11 & $3.6 \%$ & $22.4 \%$ \\
\hline
\end{tabular}

See the lists of genes in each group in the Additional file 9: Table S7

genes which are differentially regulated after infection. Of the 6508 total genes encoded by the B. thailandensis strain E555 genome, RNA-seq analysis detected expression of approximately $88 \%$ of the genes during growth in broth or in macrophages. In parallel mass spectrometry identified $42 \%$ of the predicted proteins. Similar findings have been reported in other bacteria [54-57]. Our finding that the transcriptome and proteome did not precisely mirror each other is not unexpected. In an Escherichia coli single-cell study [57] the correlation coefficient between mRNA and protein levels of the same gene averaged zero for the genes tested. Although according to the central dogma of molecular biology that transcription and translation are tightly linked in prokaryotes [58], the lack of correlation between mRNA and the encoded protein has been attributed to differences in the stability of these molecules [57] and in translation efficiency. Translation efficiency has a large impact on transcript-protein correlation. For example transcripts that have weak Shine-Dalgarno sequences are translated less efficiently $[59,60]$. Secondary structure of the mRNA [61] and codon bias (large codon bias correlates with highly expressed genes $[62,63]$ and proteins [64]) also have an influence on translation efficiency. Untranslated RNA molecules are also considered to be responsible for the differences between the transcriptomic and the proteomic results. However, the most important factor responsible for low correlations between mRNA and protein expressions is the long half-life of proteins relative to mRNAs. Transcripts are instantaneous messengers that are degraded in 3 to 8 min [65], while proteins are accumulated products with a typical half-life of $\sim 20 \mathrm{~h}$ in $E$. coli $[66,67]$. Finally, the reduced ability to recover some membrane-located or secreted proteins would limit the ability to detect them. These differences found between the transcriptomic and the proteomic data highlight the value of profiling both the transcriptome and the proteome.

Our comparison of the transcriptomes and proteomes of $B$. thailandensis strain E555 showed that most of the detected proteins were also present in the corresponding transcriptomes. We looked for transcripts and proteins that are significantly up-regulated during infection and found that an analysis of the transcriptome revealed more virulence-associated factors than an analysis of the proteome. However, although the proteome data revealed fewer virulence factors, they were identified with a higher degree of confidence. We found some examples of opposite patterns of gene and protein expression after infection (Additional file 7: Table S5). This raises the question of which method to use identifying candidate virulence factors. Among these genes we detected 1 virulence-associated factor (Fig|869,728.6.peg.5292) which was significantly up-regulated in the transcriptome but down-regulated in the proteome.

Both analyses generated false negative results. For example, deletion of the treA gene (BPSS0671) results in reduced intracellular survival of $B$. pseudomallei [68] but, compared to broth grown bacteria expression of the trehalase A gene in B. thailandensis strain E555 (Fig|869,728.6.peg.4715) was reduced during macrophage infection and the protein was not detected in culture or in macrophages. We also found numbers of other known virulence factors in the significantly down-regulated groups (Additional file 7: Table S5). This may reflect the different roles of virulence factors in different cell types or different hosts or at different stages of infection.

In summary, we combined a transcriptomic and proteomic approach to elucidate the changes involved in the adaptation of B. thailandensis strain E555 to macrophage cells. The differences found between the transcriptomic and the proteomic data suggested various post-transcriptional mechanisms and the complexity of the bacterial adaptation.

\section{Conclusions}

In contrast with $B$. thailandensis strain E264, which has been used widely as a surrogate model for $B$. pseudomal$l e i$, we show that the pattern of growth of $B$. thailandensis strain E555 in macrophages more closely mirrors that of B. pseudomallei. Using this infection model we have shown that many of the known virulence factors of $B$. pseudomallei can be identified as genes or proteins 
whose expression is elevated on the infection of macrophages. This finding further confirms the utility of $B$. thailandensis strain E555 as a surrogate for B. pseudomallei. The identification of up-regulated genes provided a more comprehensive identification of virulence factors than the identification of up-regulated proteins.

\section{Methods}

\section{Bacterial strain and cell culture growth conditions}

B. thailandensis strain E555 (gift from Patrick Tan, Genome Institute of Singapore) was grown on Luria-Bertani (LB) agar or in LB broth $(200 \mathrm{rpm})$ at $37^{\circ} \mathrm{C}$. J774A.1 mouse macrophage cells (European Collection of Cell Cultures, ECACC; Catalog No. 91051511) were maintained at $37^{\circ} \mathrm{C}$ under $5 \% \mathrm{CO}_{2}$ atmosphere in DMEM (with $4.5 \mathrm{~g} / \mathrm{l}$ Glucose, $4.0 \mathrm{mML}$-Glutamine and Sodium Pyruvate; Gibco 11,995,073) supplemented with 10\% heat inactivated fetal bovine serum (FBS Gold; PAA A15-751).

\section{Macrophage infection model}

For infection assays, $1.5 \times 10^{5}$ cells/well in 24-well cell culture plates or $6 \times 10^{6}$ cells/T75 flask (approximately $7.9 \times 10^{4}$ cells $/ \mathrm{cm}^{2}$ ) were seeded and an overnight culture of bacteria was diluted to $1.5 \times 10^{6}$ cells $/ \mathrm{ml}$ or to $6 \times 10^{7}$ cells $/ 10 \mathrm{ml}$ in Leibovitz L-15 Media (with 2.05 mM L-Glutamine; Gibco 21,083,027), respectively. J774A.1 monolayers were washed once with L-15 medium before addition of bacteria at a multiplicity of infection of $10(1 \mathrm{ml} /$ well or $10 \mathrm{ml} / \mathrm{T} 75$ flask). Murine macrophages with the bacterial cells were incubated at $37^{\circ} \mathrm{C}$ for $2 \mathrm{~h}$ to allow bacterial internalisation to occur. Extracellular bacteria were removed by washing the macrophage cells three times with warm PBS (Gibco 10,010,023). Fresh media containing kanamycin (1 mg/ $\mathrm{ml}$, which was replaced with $0.25 \mathrm{mg} / \mathrm{ml}$ kanamycin after $2 \mathrm{~h}$ of incubation) was then added to each well or flask to suppress the growth of extracellular bacteria. Infected cells were incubated in the presence of kanamycin at 37 ${ }^{\circ} \mathrm{C}$ until washed three times with PBS at appropriate time points. To determine the number of intracellular bacteria, macrophages were lysed in $0.1 \%$ Triton X-100 (Sigma-Aldrich T8787) in PBS for 5 mins, the lysis mixture was serially diluted and plated out on LB agar plates, which were then incubated overnight at $37^{\circ} \mathrm{C}$ to allow bacteria to grow. Unless otherwise stated, all infections were performed as three independent experiments, each with three technical replicates. Macrophages infected in T75 flasks were processed for transcriptome and proteome analysis as detailed below.

\section{Genome sequencing and assembly}

DNA were prepared for sequencing using a Promega Wizzard Genomic DNA Purification kit according to the manufacturer's instructions. Sequencing was performed at the University of Exeter Sequencing Facility using an 'Illumina HiSeq 2500 System' benchtop sequencing instrument (read length: $100 \mathrm{bp}$, read type: paired end). Illumina adapters were removed and sequences quality trimmed using ea-utils [69]. SPAdes [70] was used to perform a de-novo assembly of the samples. This Whole Genome Shotgun project has been deposited at DDBJ/ ENA/GenBank under the accession SJET00000000.

\section{Bacterial RNA extraction, sequencing and reverse transcription quantitative real-time PCR (RT-qPCR) for transcriptional studies}

Total RNA was extracted from infected macrophages (internalised CFU per replicate approximately $1.5 \times 10^{7}$ and $2 \times 10^{7}$ at 5 and $6 \mathrm{~h}$, respectively) and from bacterial cultures, and the RNA integrity number (RIN) was determined. RIN was more than 9 with all the extracts indicating no evidence of RNA degradation. After the final washing step at 5 or 6 -h post-infection (2-h infection +3 or 4 -h kanamycin treatment), $2 \mathrm{ml}$ TRIzol $^{\circ}$ Reagent (Invitrogen 15,596,026) was added to the flasks to lyse both the macrophage and bacterial cells. Cell lysates were stored at $-80^{\circ} \mathrm{C}$ until further processing. When thawed, total RNA (total eukaryotic and total prokaryotic RNA) was extracted using the Direct-zol ${ }^{\mathrm{Tm}}$ RNA MiniPrep Kit (Zymo Research R2052). Contaminating DNA was digested by DNAse I treatment (Ambion AM2222) which was confirmed by reverse transcriptase PCR (Qiagen OneStep RT-PCR Kit 210,212) using primers glt1-F (5`CGCACCATGACATCTATTCG $3^{`}$ ) vs $g l t 1-\mathrm{R}$ (5` ACCGGATTGACGTTCTTCAG $\left.3^{\prime}\right)$. DNA-free RNA was treated with the TruSeq RNA Library Preparation Kit v2 (Illumina RS-122-2001) and the Ribo-Zero Gold rRNA Removal Kit (Epidemiology) (Illumina MRZE724). Eukaryotic mRNA was first removed using poly-A selection, the remaining RNA was then enriched for bacterial mRNA by depleting both the bacterial and macrophage rRNA and the RNA-seq libraries were prepared to the guidelines of the manufacturer. Control bacterial mRNA was obtained from the overnight broth cultures of bacteria which were used to infect macrophage cells. RNA from broth culture was isolated as described above (including the poly-A depletion step). RNA was isolated from 3 separate assays (biological replicates) from both infected macrophages and control bacteria. RNA-seq libraries were created using the Illumina TruSeq Stranded mRNA Library Prep Kit according to the manufacturer's protocol. The concentration, quality and integrity of all RNA and DNA samples were analysed using the Agilent 2100 Bioanalyser. Sequencing was performed at the University of Exeter Sequencing Facility using an 'Illumina MiSeq System' benchtop sequencing instrument (read length: 
75 bp, read type: paired end). Reads from RNASeq were mapped to the B. thailandensis strain E555 genome assembly using Tophat [71]. Cufflinks [72] was used for transcript assembly of individual samples. All assemblies were merged to create a reference transcript, which was used to calculate gene counts with HTSeq [73]. DESeq [74] was then used to find differentially expressed genes. Transcripts with a $p$-value $<0.05$ and more than 2 -fold differential expression were considered significantly expressed.

The preparation of cDNA from total RNA extracted from culture and infected macrophages was carried out using the Superscript III Reverse Transcriptase Synthesis System (Invitrogen 18,080,051) with random hexamers according to the manufacturer's recommendations. RT-qPCR was performed with primers annealing to internal regions of the target genes (Additional file 10: Table S8) using Platinum ${ }^{\circ}$ SYBR $^{\circ}$ Green qPCR SuperMix-UDG according to the manufacturer's manual (Invitrogen 11,733,038). For the adjustment of cDNA amounts, the housekeeping gene 23S rRNA [75] was used as internal standard.

\section{Bacterial protein extraction and mass spectrometric analysis for proteomic studies}

In contrast to the RNA, prokaryotic and eukaryotic proteins are indistinguishable. Therefore, intact bacterial cells were first extracted from infected macrophages and bacterial proteins were then isolated from the bacterial cells. Macrophages were infected as described above using the same conditions as used for the $6 \mathrm{~h}$ transcriptome samples (i.e. internalised CFU per replicate approximately $2 \times 10^{7}$ at $6 \mathrm{~h}$ post-infection). Following the final washing step at 6-h post-infection (2-h infection + 4-h kanamycin treatment) infected macrophages in T75 flasks were lysed in $0.1 \%$ Triton X-100 in PBS for 5 mins to release the intracellular bacteria and whole bacterial cells were isolated using a modified immunomagnetic separation technique described previously by Twine et al. [76]. Briefly, Dynabeads ${ }^{\circ}$ M-270 Epoxy (Life Technologies 14311D) were covalently attached to goat $\alpha$-mouse IgG $(\mathrm{H}+\mathrm{L})$ secondary antibodies (Invitrogen A16068) as per the manufacturer's instructions (20 $\mu \mathrm{g}$ of antibodies per $1 \mathrm{mg}$ of magnetic beads were used) and magnetic beads coated with secondary antibodies were labelled with mouse $\alpha$-capsule primary antibodies (CPS $4 \mathrm{~V} 1 \mathrm{H} 12$ [12]) $(17.5 \mu \mathrm{g}$ of $\alpha$-CPS antibodies per $1 \mathrm{mg}$ of bead - secondary antibody complexes), which recognise surface antigens of $B$. thailandensis strain E555 cells. Magnetic bead $-\alpha$-mouse $-\alpha$-CPS complexes were then used to purify the bacteria. $1 \mathrm{mg}$ of beads coated with both antibodies was mixed with macrophage cell lysate per T75 flask and incubated for 25 min with constant agitation $(35 \mathrm{rpm})$ at $4{ }^{\circ} \mathrm{C}$ to capture the bacterial cells. The beads-bacteria complexes were separated from the cell debris on a magnetic stand, washed, and immediately re-suspended in BugBuster ${ }^{\circ}$ Protein Extraction Reagent (Novagen 70,584) to lyse the bacterial cells and release the proteins. Bacterial purification was completed in about $45 \mathrm{~min}$. Control extracts included bacterial proteins isolated by BugBuster Protein Extraction Reagent from the overnight broth cultures of bacteria which were used to infect macrophage cells.

Mass spectrometric analysis of protein samples isolated from 3 biological replicates of both infected macrophages and bacterial cultures was done by the University of Bristol Proteomics Facility. Proteomics was performed as described previously using an UltiMate ${ }^{\mathrm{Tu}}$ 3000 nano HPLC system in line with an LTQ-Orbitrap Velos mass spectrometer (Thermo Scientific) [77]. The raw data files were processed and quantified using Proteome Discoverer software v1.2 (Thermo Scientific) and searched against $B$. thailandensis strain E555 RAST ORFs using the SEQUEST algorithm. The reverse database search option was enabled and all peptide data was filtered to satisfy false discovery rate (FDR) of $5 \%$. Abundance of each protein in each sample was calculated using the average area measurements of the three most abundant peptides matching to each protein (Top3 method) [78]. This value was then expressed in the fraction of the signal derived from the 100 most abundant proteins detected in each sample which was then compared for each protein in LB broth and macrophages. Statistical significance of the fold change difference was calculated using $\mathrm{R}$ with q-values reported after $5 \%$ FDR correction. All proteins with a q-value $<0.05$ and more than 2 -fold change difference were considered significantly regulated.

\section{Online and bioinformatic tools}

Genome sequence of B. thailandensis strain E555 was annotated using the web-based RAST server (Rapid Annotation using Subsystem Technology) [44]. Cellular localisation of the predicted proteins encoded in the $B$. thailandensis strain E555 genome was predicted using PSORTb 3.0 [79] (Additional file 3: Table S1.D). Protein homologs in B. pseudomallei strain K96243, B. thailandensis strain E555 and B. thailandensis strain E264 were identified by blast search. Proteins were considered homologs if they met the following criteria: e value $\leq 0.000001$ and (i) sequence identity $>30 \%$ if alignment length/query length $>90 \%$ [80], (ii) sequence identity > $40 \%$ if alignment length/query length between 70 and $90 \%$, (iii) sequence identity $>55 \%$ if alignment length/ query length between 50 and $70 \%$ (Additional file 3: Table S1.C). Correlation coefficients between the samples were calculated using the formula built-in the Microsoft Excel Software. B. thailandensis strain E555 
genes were classified into functional categories based on clusters of orthologous gene (COG) designations; functional classes of $B$. thailandensis genes and proteins were determined based on the categorisation of their homologs in B. pseudomallei (Sheet C of Additional file 4: Table S2 in reference [81], Additional file 3: Table S1 D). Statistical analysis of growth curves was performed using Graph Pad Prism 5.03 software One-way ANOVA Kruskal-Wallis test with Dunns post test. DESeq [74] was used to determine fold change and the $p$ value of differential expression in the RNASeq data. Statistical significance ( $q$ value) of the fold change difference in the proteome was calculated using $\mathrm{R}$. To identify pathways that are up- or down-regulated during infection we used Keg Array 1.2.4a software which maps the genes/proteins to KEGG pathways. Up-regulation or down-regulation of genes/proteins with at least 1.5-fold increase or decrease in expression difference was considered to be necessary or dispensable respectively during macrophage infection.

\section{Additional file}

Additional file 1: Figure S1. Abundance of transcripts detected in the bacterial transcriptome both at $5 \mathrm{~h}$ and $6 \mathrm{~h}$ post infection.

Figure S2. Abundance of bacterial transcripts detected in culture and in macrophages. Figure S3. Abundance of bacterial proteins detected in culture and in macrophages. Figure S4. Volcano plots of gene expression for $B$. thailandensis strain E555 during macrophage infection (versus in vitro growth) at transcript and protein level. (DOCX 1997 kb)

Additional file 2: Supplementary References. (DOCX $17 \mathrm{~kb}$ )

Additional file 3: Table S1. Details of B. thailandensis strain E555 genes and proteins. (XLSX $6051 \mathrm{~kb}$ )

Additional file 4: Table S2. Gene expression results and details of the genes subjected to RT-qPCR analysis. (XLSX $15 \mathrm{~kb}$ )

Additional file 5: Table S3. Transcripts detected in vitro and in vivo. (XLSX $2144 \mathrm{~kb}$ )

Additional file 6: Table S4. Proteins detected in vitro and in vivo. (XLSX $1095 \mathrm{~kb}$ )

Additional file 7: Table S5. Significantly regulated genes, capsule expression and all expression data. (XLSX $2279 \mathrm{~kb}$ )

Additional file 8: Table S6. Known virulence genes. (XLSX 208 kb)

Additional file 9: Table S7. Lists of genes in each group shown in Table 2. (XLSX $321 \mathrm{~kb}$ )

Additional file 10: Table S8. Primers used in RT-qPCR. (DOCX 15 kb)

\section{Abbreviations}

CFU: Colony forming unit; CFU: Colony-forming unit; COG: Clusters of orthologous gene; CPS: Capsule polysaccharide; DMEM: Dulbecco's modified Eagle's medium; DNA: Deoxyribose nucleic acid; LB: Luria-Bertani; mRNA: Messenger ribonucleic acid; RAST: Rapid Annotation using Subsystem Technology; RNA-Seq: RNA sequencing; RT-qPCR: Reverse transcription quantitative real-time polymerase chain reaction; SDS-PAGE: Sodium dodecyl sulfate polyacrylamide gel electrophoresis; T3SS: Type III secretion system; T6SS: Type VI secretion system

\section{Acknowledgements}

Exeter Sequencing Service and Computational core facilities at University of Exeter was generously supported by a Medical Research Council Clinical Infrastructure award (MR/M008924/1), a Wellcome Trust Institutional Strategic
Support Fund (WT097835MF), a Wellcome Trust Multi User Equipment Award (WT101650MA) and a BBSRC LOLA award (BB/K003240/1). We wish to thank Kate Heesom for her help with the mass spectrometric analysis.

\section{Funding}

This work was funded by the United Kingdom Ministry of Defense (Project Dstlx1000083635), published with the permission of the Defence Science and Technology Laboratory on behalf of the Controller of HMSO.

\section{Availability of data and materials}

The datasets used and analyzed during the current study are available from the corresponding author on reasonable request.

\section{Authors' contributions}

AK did all laboratory works, analysed and interpreted the data, and drafted the manuscript. AK, CM and RT designed the study. RT coordinated the study and revised the manuscript. CM, AS and JP also revised the manuscript critically for important intellectual content. All authors read and approved the final version of the manuscript.

Ethics approval and consent to participate Not applicable.

\section{Consent for publication}

Not applicable.

\section{Competing interests}

The authors declare that they have no competing interests.

\section{Publisher's Note}

Springer Nature remains neutral with regard to jurisdictional claims in published maps and institutional affiliations.

\section{Author details}

${ }^{1}$ College of Life and Environmental Sciences, University of Exeter, Geoffrey Pope Building, Stocker Road, Exeter EX4 4QD, UK. ${ }^{2}$ CBR Division, Defence Science and Technology Laboratory, Porton Down, Salisbury SP4 0JQ, UK.

Received: 6 December 2018 Accepted: 30 April 2019

Published online: 15 May 2019

\section{References}

1. Limmathurotsakul D, Golding N, Dance DA, Messina JP, Pigott DM, Moyes CL, Rolim DB, Bertherat E, Day NP, Peacock SJ, et al. Predicted global distribution of Burkholderia pseudomallei and burden of melioidosis. Nat Microbiol. 2016;1:15008.

2. Wiersinga WJ, Virk HS, Torres AG, Currie BJ, Peacock SJ, Dance DAB, Limmathurotsakul D. Melioidosis. Nat Rev Dis Primers. 2018;4:17107.

3. Perumal Samy R, Stiles BG, Sethi G, Lim LHK. Melioidosis: clinical impact and public health threat in the tropics. PLoS Negl Trop Dis. 2017;11(5):e0004738.

4. Peacock SJ. Melioidosis. Curr Opin Infect Dis. 2006;19(5):421-8.

5. Dance DAB. Melioidosis. Curr Opin Infect Dis. 2002;15:127-32.

6. Gan YH, Chua KL, Chua HH, Liu BP, Hii CS, Chong HL, Tan P. Characterization of Burkholderia pseudomallei infection and identification of novel virulence factors using a Caenorhabditis elegans host system. Mol Microbiol. 2002:44:1185-97.

7. Holden MTG, Titball RW, Peacock SJ, Cerdeno-Tarraga AM, Atkins T, Crossman LC, Pitt T, Churcher C, Mungall K, Bentley SD, et al. Genomic plasticity of the causative agent of melioidosis, Burkholderia pseudomallei. Proc Natl Acad Sci U S A. 2004;101(39):14240-5.

8. Howe C, Sampath A, Spotnitz M. The pseudomallei group: a review. J Infect Dis. 1971;124(6):598-606.

9. Zilinskas RA. A brief history of biological weapons programmes and the use of animal pathogens as biological warfare agents. Rev Sci Tech. 2017;36(2): 415-22.

10. Titball RW, Burtnick MN, Bancroft GJ, Brett P. Burkholderia pseudomallei and Burkholderia mallei vaccines: are we close to clinical trials? Vaccine. 2017; 35(44):5981-9.

11. Dance D. Treatment and prophylaxis of melioidosis. Int J Antimicrob Agents. 2014;43(4):310-8. 
12. Vander Broek CW, Stevens JM. Type III secretion in the Melioidosis pathogen Burkholderia pseudomallei. Front Cell Infect Microbiol. 2017;7:255.

13. Stone JK, DeShazer D, Brett PJ, Burtnick MN. Melioidosis: molecular aspects of pathogenesis. Expert Rev Anti-Infect Ther. 2014;12(12):1487-99.

14. Reckseidler-Zenteno SL, DeVinney R, Woods DE. The capsular polysaccharide of Burkholderia pseudomallei contributes to survival in serum by reducing complement factor C3b deposition. Infect Immun. 2005;73(2):1106-15.

15. Moule MG, Hemsley CM, Seet Q, Guerra-Assuncao JA, Lim J, Sarkar-Tyson M, Clark TG, Tan PB, Titball RW, Cuccui J, et al. Genome-wide saturation mutagenesis of Burkholderia pseudomallei K96243 predicts essential genes and novel targets for antimicrobial development. mBio. 2014;5(1):e00926-13.

16. Cuccui J, Easton A, Bancroft G, Oyston PCF, Titball RW, Wren BW. Development of signature tagged mutagenesis in Burkholderia pseudomallei to identify mutants important in survival, attenuation and pathogenesis. Infect Immun. 2007:75:1186-95.

17. Brett P, Deshazer D, Woods D. Burkholderia thailandensis sp. nov., a Burkholderia pseudomallei-like species. Int J Syst Bacteriol. 1998;48:317-20.

18. Yu Y, Kim HS, Chua HH, Lin CH, Sim SH, Lin D, Derr A, Engels R, Deshazer D, Birren B, et al. Genomic patterns of pathogen evolution revealed by comparison of Burkholderia pseudomallei, the causative agent of melioidosis, to avirulent Burkholderia thailandensis. BMC Microbiol. 2006;6(46):46.

19. Le Guillouzer S, Groleau MC, Deziel E. The complex quorum sensing circuitry of Burkholderia thailandensis is both hierarchically and Homeostatically organized. MBio. 2017;8(6):e01861-17.

20. Gupta A, Bedre R, Thapa SS, Sabrin A, Wang G, Dassanayake M, Grove A. Global awakening of cryptic biosynthetic gene clusters in Burkholderia thailandensis. ACS Chem Biol. 2017;12(12):3012-21.

21. Bayliss M, Donaldson MI, Nepogodiev SA, Pergolizzi G, Scott AE, Harmer NJ, Field RA, Prior JL. Structural characterisation of the capsular polysaccharide expressed by Burkholderia thailandensis strain E555:: wbil (pKnock-KmR) and assessment of the significance of the 2-O-acetyl group in immune protection. Carbohydr Res. 2017:452:17-24.

22. Whiteley L, Haug M, Klein K, Willmann M, Bohn E, Chiantia S, Schwarz S. Cholesterol and host cell surface proteins contribute to cell-cell fusion induced by the Burkholderia type VI secretion system 5. PloS one. 2017; 12(10):e0185715.

23. Jimenez V Jr, Moreno R, Kaufman E, Hornstra H, Settles E, Currie BJ, Keim P, Monroy FP. Effects of binge alcohol exposure on Burkholderia thailandensisalveolar macrophage interaction. Alcohol. 2017;64:55-63.

24. Whiteley L, Meffert T, Haug M, Weidenmaier C, Hopf V, Bitschar K, Schittek B, Kohler C, Steinmetz I, West TE, et al. Entry, intracellular survival, and multinucleated-Giant-cell-forming activity of Burkholderia pseudomallei in human primary phagocytic and nonphagocytic cells. Infect Immun. 2017; 85(10):e00468-17.

25. Si M, Wang Y, Zhang B, Zhao C, Kang Y, Bai H, Wei D, Zhu L, Zhang L, Dong $T G$, et al. The type VI secretion system engages a redox-regulated dualfunctional Heme transporter for zinc acquisition. Cell Rep. 2017;20(4):949-59.

26. Bond TEH, Sorenson AE, Schaeffer PM. Functional characterisation of Burkholderia pseudomallei biotin protein ligase: a toolkit for anti-melioidosis drug development. Microbiol Res. 2017;199:40-8.

27. Mao D, Bushin LB, Moon K, Wu Y, Seyedsayamdost MR. Discovery of scmR as a global regulator of secondary metabolism and virulence in Burkholderia thailandensis E264. Proc Natl Acad Sci U S A. 2017;114(14): E2920-e2928.

28. Fang Y, Chen H, Hu Y, Li Q, Hu Z, Ma T, Mao X. Burkholderia pseudomalleiderived miR-3473 enhances NF-kappaB via targeting TRAF3 and is associated with different inflammatory responses compared to Burkholderia thailandensis in murine macrophages. BMC Microbiol. 2016;16(1):283.

29. Custodio R, McLean CJ, Scott AE, Lowther J, Kennedy A, Clarke DJ, Campopiano DJ, Sarkar-Tyson M, Brown AR. Characterization of secreted sphingosine-1-phosphate lyases required for virulence and intracellular survival of Burkholderia pseudomallei. Mol Microbiol. 2016;102(6):1004-19.

30. Benanti EL, Nguyen CM, Welch MD. Virulent Burkholderia species mimic host actin polymerases to drive actin-based motility. Cell. 2015;161(2):348-60.

31. Shan J, Korbsrisate S, Withatanung P, Adler NL, Clokie MR, Galyov EE. Temperature dependent bacteriophages of a tropical bacterial pathogen. Front Microbiol. 2014;5:599

32. Peano C, Chiaramonte F, Motta S, Pietrelli A, Jaillon S, Rossi E, Consolandi C, Champion OL, Michell SL, Freddi L, et al. Gene and protein expression in response to different growth temperatures and oxygen availability in Burkholderia thailandensis. PLoS One. 2014;9(3):e93009.
33. Wagley S, Hemsley C, Thomas R, Moule MG, Vanaporn M, Andreae C, Robinson M, Goldman S, Wren BW, Butler CS, et al. The twin arginine translocation system is essential for aerobic growth and full virulence of Burkholderia thailandensis. J Bacteriol. 2014;196(2):407-16.

34. Gallagher LA, Ramage E, Patrapuvich R, Weiss E, Brittnacher M, Manoil C. Sequence-defined transposon mutant library of Burkholderia thailandensis. MBio. 2013;4(6):e00604-13.

35. Thomas RJ, Hamblin KA, Armstrong SJ, Muller CM, Bokori-Brown M, Goldman S, Atkins HS, Titball RW. Galleria mellonella as a model system to test the pharmacokinetics and efficacy of antibiotics against Burkholderia pseudomallei. Int J Antimicrob Agents. 2013;41(4):330-6.

36. Scott AE, Twine SM, Fulton KM, Titball RW, Essex-Lopresti AE, Atkins TP, Prior $J$. Flagellar glycosylation in Burkholderia pseudomallei and Burkholderia thailandensis. J Bacteriol. 2011;193(14):3577-87.

37. Schwarz S, West TE, Boyer F, Chiang WC, Carl MA, Hood RD, Rohmer L, Tolker-Nielsen T, Skerrett SJ, Mougous JD. Burkholderia type VI secretion systems have distinct roles in eukaryotic and bacterial cell interactions. PLoS Pathog. 2010;6(8):e1001068.

38. Kespichayawattana W, Intachote P, Utaisincharoen P, Sirisinha S. Virulent Burkholderia pseudomallei is more efficient than avirulent Burkholderia thailandensis in invasion of and adherence to cultured human epithelial cells. Microb Pathog. 2004;36(5):287-92.

39. Wand ME, Muller CM, Titball RW, Michell SL. Macrophage and Galleria mellonella infection models reflect the virulence of naturally occurring isolates of B. pseudomallei, B. thailandensis and B. oklahomensis. BMC Microbiol. 2011;11(1):11.

40. Sim BM, Chantratita N, Ooi WF, Nandi T, Tewhey R, Wuthiekanun V, Thaipadungpanit J, Tumapa S, Ariyaratne P, Sung WK, et al. Genomic acquisition of a capsular polysaccharide virulence cluster by nonpathogenic Burkholderia isolates. Genome Biol. 2010;11(8):R89.

41. Jenner D, Ducker C, Clark G, Prior J, Rowland CA: Using multispectral imaging flow cytometry to assess an in vitro intracellular Burkholderia thailandensis infection model cytometry part a volume 89, issue 4. In: Cytometry Part A. vol. 89; 2016: 328-337.

42. Cuccui J, Milne TS, Harmer N, George AJ, Harding SV, Dean RE, Scott AE, Sarkar-Tyson M, Wren BW, Titball RW, et al. Characterization of the Burkholderia pseudomallei K96243 capsular polysaccharide I coding region. Infect Immun. 2012;80(3):1209-21.

43. Cuccui J, Easton A, Chu KK, Bancroft GJ, Oyston PC, Titball RW, Wren BW. Development of signature-tagged mutagenesis in Burkholderia pseudomallei to identify genes important in survival and pathogenesis. Infect Immun. 2007;75(3):1186-95.

44. Overbeek R, Olson R, Pusch GD, Olsen GJ, Davis JJ, Disz T, Edwards RA, Gerdes S, Parrello B, Shukla M, et al. The SEED and the rapid annotation of microbial genomes using subsystems technology (RAST). Nucleic Acids Res. 2014;42(Database issue):D206-14

45. Vanaporn M, Vattanaviboon $\mathrm{P}$, Thongboonkerd V, Korbsrisate S. The rpoE operon regulates heat stress response in Burkholderia pseudomallei. FEMS Microbiol Lett. 2008;284(2):191-6.

46. Kumar A, Mayo M, Trunck LA, Cheng AC, Currie BJ, Schweizer HP. Expression of resistance-nodulation-cell-division efflux pumps in commonly used Burkholderia pseudomallei strains and clinical isolates from northern Australia. Trans R Soc Trop Med Hyg. 2008;102(Suppl 1):S145-51.

47. Rey S, Gardy JL, Brinkman FS. Assessing the precision of high-throughput computational and laboratory approaches for the genome-wide identification of protein subcellular localization in bacteria. BMC Genomics. 2005;6:162.

48. Shalom G, Shaw JG, Thomas MS. In vivo expression technology identifies a type $\mathrm{VI}$ secretion system locus in Burkholderia pseudomallei that is induced upon invasion of macrophages. Microbiology. 2007;153(Pt 8):2689-99.

49. Chen $Y$, Schroder I, French CT, Jaroszewicz A, Yee XJ, Teh BE, Toesca IJ, Miller JF, Gan YH. Characterization and analysis of the Burkholderia pseudomallei BsaN virulence regulon. BMC Microbiol. 2014;14:206.

50. Lazar Adler NR, Stevens MP, Dean RE, Saint RJ, Pankhania D, Prior JL, Atkins TP, Kessler B, Nithichanon A, Lertmemongkolchai G, et al. Systematic mutagenesis of genes encoding predicted autotransported proteins of Burkholderia pseudomallei identifies factors mediating virulence in mice, net intracellular replication and a novel protein conferring serum resistance. PLoS One. 2015;10(4):e0121271.

51. Sarkar-Tyson M, Thwaite JE, Harding SV, Smither SJ, Oyston PC, Atkins TP, Titball RW. Polysaccharides and virulence of Burkholderia pseudomallei. J Med Microbiol. 2007:56(Pt 8):1005-10. 
52. Zhang JH, Quigley NB, Gross DC. Analysis of the syrP gene, which regulates syringomycin synthesis by Pseudomonas syringae pv. Syringae. Appl Environ Microbiol. 1997;63(7):2771-8.

53. Phewkliang A, Wongratanacheewin S, Chareonsudjai S. Role of Burkholderia pseudomallei in the invasion, replication and induction of apoptosis in human epithelial cell lines. Southeast Asian J Trop Med Public Health. 2010; 41(5):1164-76

54. Munir RI, Spicer V, Krokhin OV, Shamshurin D, Zhang X, Taillefer M, Blunt W, Cicek N, Sparling R, Levin DB. Transcriptomic and proteomic analyses of core metabolism in Clostridium termitidis CT1112 during growth on alphacellulose, xylan, cellobiose and xylose. BMC Microbiol. 2016;16:91.

55. Gygi SP, Rochon Y, Franza BR, Aebersold R. Correlation between protein and mRNA abundance in yeast. Mol Cell Biol. 1999;19(3):1720-30.

56. Yeung ES. Genome-wide correlation between mRNA and protein in a single cell. Angew Chem Int Ed Engl. 2011;50(3):583-5.

57. Taniguchi Y, Choi PJ, Li GW, Chen H, Babu M, Hearn J, Emili A, Xie XS. Quantifying E. coli proteome and transcriptome with single-molecule sensitivity in single cells. Science. 2010;329(5991):533-8.

58. Gowrishankar J, Harinarayanan R. Why is transcription coupled to translation in bacteria? Mol Microbiol. 2004;54(3):598-603.

59. Shine J, Dalgarno L. The 3'-terminal sequence of Escherichia coli $16 \mathrm{~S}$ ribosomal RNA: complementarity to nonsense triplets and ribosome binding sites. Proc Natl Acad Sci U S A. 1974;71(4):1342-6.

60. Shine J, Dalgarno L. Determinant of cistron specificity in bacterial ribosomes. Nature. 1975:254(5495):34-8

61. Grossman AD, Zhou YN, Gross C, Heilig J, Christie GE, Calendar R. Mutations in the rpoH (htpR) gene of Escherichia coli K-12 phenotypically suppress a temperature-sensitive mutant defective in the sigma 70 subunit of RNA polymerase. J Bacteriol. 1985;161(3):939-43.

62. Jansen R, Bussemaker HJ, Gerstein M. Revisiting the codon adaptation index from a whole-genome perspective: analyzing the relationship between gene expression and codon occurrence in yeast using a variety of models. Nucleic Acids Res. 2003;31(8):2242-51

63. Kliman RM, Irving N, Santiago M. Selection conflicts, gene expression, and codon usage trends in yeast. J Mol Evol. 2003;57(1):98-109.

64. Wu G, Nie L, Freeland SJ. The effects of differential gene expression on coding sequence features: analysis by one-way ANOVA. Biochem Biophys Res Commun. 2007:358(4):1108-13.

65. Bernstein JA, Khodursky AB, Lin PH, Lin-Chao S, Cohen SN. Global analysis of mRNA decay and abundance in Escherichia coli at single-gene resolution using two-color fluorescent DNA microarrays. Proc Natl Acad Sci U S A. 2002;99(15):9697-702.

66. Koch AL, Levy HR. Protein turnover in growing cultures of Escherichia coli. J Biol Chem. 1955;217(2):947-57.

67. Mandelstam J. Turnover of protein in growing and non-growing populations of Escherichia coli. Biochem J. 1958;69(1):110-9.

68. Vanaporn M, Sarkar-Tyson M, Kovacs-Simon A, Ireland PM, Pumirat P, Korbsrisate S, Titball RW, Butt A. Trehalase plays a role in macrophage colonization and virulence of Burkholderia pseudomallei in insect and mammalian hosts. Virulence. 2017;8(1):30-40.

69. ea-utils : "Command-line tools for processing biological sequencing data" [https://github.com/ExpressionAnalysis/ea-utils].

70. Bankevich A, Nurk S, Antipov D, Gurevich AA, Dvorkin M, Kulikov AS, Lesin VM, Nikolenko SI, Pham S, Prjibelski AD, et al. SPAdes: a new genome assembly algorithm and its applications to single-cell sequencing. J Comput Biol. 2012;19(5):455-77.

71. Trapnell C, Pachter L, Salzberg SL. TopHat: discovering splice junctions with RNA-Seq. Bioinformatics. 2009;25(9):1105-11.

72. Trapnell C, Roberts A, Goff L, Pertea G, Kim D, Kelley DR, Pimentel H, Salzberg SL, Rinn JL, Pachter L. Differential gene and transcript expression analysis of RNA-seq experiments with TopHat and cufflinks. Nat Protoc. 2012;7(3):562-78.

73. Anders S, Pyl PT, Huber W. HTSeq--a Python framework to work with highthroughput sequencing data. Bioinformatics. 2015;31(2):166-9.

74. Anders S, Huber W. Differential expression analysis for sequence count data. Genome Biol. 2010;11(10):R106.

75. Jitprasutwit $S$, Ong C, Juntawieng N, Ooi WF, Hemsley CM, Vattanaviboon P, Titball RW, Tan P, Korbsrisate S. Transcriptional profiles of Burkholderia pseudomallei reveal the direct and indirect roles of sigma $E$ under oxidative stress conditions. BMC Genomics. 2014;15:787.
76. Twine SM, Mykytczuk NC, Petit MD, Shen H, Sjostedt A, Wayne Conlan J, Kelly JF. In vivo proteomic analysis of the intracellular bacterial pathogen, Francisella tularensis, isolated from mouse spleen. Biochem Biophys Res Commun. 2006;345(4):1621-33.

77. Goggs R, Harper MT, Pope RJ, Savage JS, Williams CM, Mundell SJ, Heesom KJ, Bass M, Mellor H, Poole AW. RhoG protein regulates platelet granule secretion and thrombus formation in mice. J Biol Chem. 2013;288(47): 34217-29.

78. Ahrne E, Molzahn L, Glatter T, Schmidt A. Critical assessment of proteomewide label-free absolute abundance estimation strategies. Proteomics. 2013; 13(17):2567-78

79. Yu NY, Wagner JR, Laird MR, Melli G, Rey S, Lo R, Dao P, Sahinalp SC, Ester M, Foster $L$, et al. PSORTb 3.0: improved protein subcellular localization prediction with refined localization subcategories and predictive capabilities for all prokaryotes. Bioinformatics. 2010;26(13):1608-15.

80. Rost B. Twilight zone of protein sequence alignments. Protein Eng. 1999; 12(2):85-94.

81. Ooi WF, Ong C, Nandi T, Kreisberg JF, Chua HH, Sun G, Chen Y, Mueller C, Conejero L, Eshaghi M, et al. The condition-dependent transcriptional landscape of Burkholderia pseudomallei. PLoS Genet. 2013;9(9):e1003795.

\section{Ready to submit your research? Choose BMC and benefit from:}

- fast, convenient online submission

- thorough peer review by experienced researchers in your field

- rapid publication on acceptance

- support for research data, including large and complex data types

- gold Open Access which fosters wider collaboration and increased citations

- maximum visibility for your research: over $100 \mathrm{M}$ website views per year

At BMC, research is always in progress.

Learn more biomedcentral.com/submissions 